\title{
Control de Constitucionalidad/Convencionalidad en la Unión Europea y el Sistema del Reenvío Perjudicial
}

\section{Control of Constitutionality/Conventionality in the European Union and the Preliminary Reference System}

\author{
Eduardo Biacchi Gomes ${ }^{1}$ \\ Edileny Tomé da Mata ${ }^{23}$ \\ ${ }^{1}$ Centro Universitário PPGD Uni Brasil, Tarumã, Curitiba, PR, Brasil \\ ${ }^{2}$ Universidad Pablo de Olavide, Sevilla, Espanha \\ ${ }^{3}$ Instituto Joaquin Herrera Flores, Sevilla, Espanha
}

Resumen: Este trabajo aborda la cuestión del control de constitucionalidad/convencionalidad en el sistema europeo, considerado uno de los más eficaces en comparación con otros controles regionales, dada las características de los vínculos entre los Estados miembros y el sistema supranacional. Primero cuestionamos si existe una Constitución en Europa, después presentamos la estructura básica del control de constitucionalidad/convencionalidad en Europa y, finalizamos con dos casos prácticos de reenvío prejudicial que ponen en jaque parte de la eficacia de este sistema.

Palabras clave: Control de Convencionalidad. Constitucionalidad. Europa. Migrantes.

\begin{abstract}
In this manuscript we raise the question of control of constitutionality/ conventionality in the European system, which is considered the most effective among the regional systems of control of constitutionality/ conventionality due to the relationship between the members' states and the supranational system. In this sense, we start asking if whether there is or not a Constitution in Europe, then we present the basic structure of control of constitutionality/conventionality in Europe, and we finish by presenting two cases of preliminary reference system that challenge part of the effectiveness of this system.
\end{abstract}

Keywords: Control of Conventionality. Constitutionality. Europe. Migrants.

Recebido em: 05/10/2018

Revisado em: 07/01/2019

Aprovado em: 04/02/2019 


\section{Consideraciones Iníciales: ¿Hay Una Constitución En La Unión Europea?}

La Unión Europea (en adelante UE) es un bloque económico en régimen de mercado común y unión monetaria en el que se establecen políticas hacia las cuatro libertades de mercado (libre circulación de bienes, mercaderías, servicios y capitales). En la concreción de esos objetivos el Tratado de Lisboa (2009) constituye una de las herramientas importante en la efectividad de las normas del bloque.

En el sentido señalado en el párrafo anterior se encuadra parte del Derecho de la UE, que es un derecho sui generis, que surge del derecho internacional, pero tiene como característica la independencia y autonomía frente al derecho interno y el derecho internacional. Así pues, se puede hablar de la efectividad de las normas del bloque dentro de los Estados miembros, que tienen la primacía frente el orden jurídico interno de los Estados y la uniformidad de la interpretación y de la aplicación de dichas normativas por parte de los tribunales nacionales, a través del reenvío prejudicial.

Además podemos afirmar que en la UE existe un cierto control de constitucionalidad establecido formalmente que puede ser ejercido tanto por parte del Tribunal de Justicia de la Unión Europea o por parte de los tribunales nacionales, siempre en conexión con las normas de este órgano regional.

Una cuestión que creemos de gran relevancia en el marco del control del debate sobre el control de constitucionalidad/convencionalidad en la Unión es que empecemos planteando si existe o no una Constitución en la UE. Sobre ello, y sin interés en desarrollar una tesis sobre la cuestión y abordar todos los argumentos al respecto, recogemos aquí visiones de algunos especialistas que consideran que el Tratado de Constitución de la UE tiene unos mínimos irreductibles para ser considerado una Constitución desde el punto de vista de Loewenstein, aunque sería necesario tener en cuenta ciertas características necesarias caso el Estado sea federal o central asumiendo así los puntos de vista de Wheare sobre la materia (MARTÍNEZ, 2005). 
Según Wheare caso se trate de un gobierno federal, como fueron las intenciones iníciales de algunos de los fundadores de la Unión Europea, sería necesario que se cumpliera ciertas condiciones: delimitar las esferas de autoridad del Gobierno central y de los gobiernos de las partes constitutivas; fijar limitaciones a determinados cuerpos legislativos; y asegurar la supremacía de la Constitución sobre éstos, impidiendo eventualmente sea cual fuere la forma en que la Constitución puede ser enmendada, no llegue a verse subordinada, sobre todo en lo que respeta a la división de poderes, ni al cuerpo legislativo central ni a los cuerpos legislativos de las partes constitutivas (WHEARE, 1975, p. 39).

Otros consideran que el Tratado constitucional europeo puede ser considerado una constitución europea en sentido material (PEREIRA, 2008, p. 5), o que tiene ciertos elementos constitucionales (CANCELA, 2001, p. 279).

Martínez Estay en su trabajo sobre el sistema europeo continental de justicia constitucional considera que la Constitución de la Unión Europea tiene carácter "normativo directo" (MARTÍNEZ, 2005, p. 61).

Balaguer Callejón afirma que falta en Europa partidos políticos de alcance europeo así como medios de comunicación europeos a fin de construir un espacio constitucional europeo (BALAGUER, 2012a). Explica Callejón que las principales razones de esta 'crisis constitucional' europea se debe, por un lado, al control del poder y la garantía de los derechos constitucionales, que se ven dificultados por la traslación de las decisiones a un espacio europeo sin ciudadanía. Y, por otro a la canalización de los conflictos internos, que se ven imposibilitados por el propio modelo de integración, que transforma los conflictos sociales y políticos internos en conflictos nacionales frente a Europa (BALAGUER, 2013b, p. 102).

Ya desde el punto de vista material y concreto de la experiencia europea es menester resaltar que hubo un intento fallido de construir un Tratado constitutivo de la Unión Europea en el año 2004 como consecuencia de los referendos de Francia y Holanda (MARTíNEZ, 2012), que según Millán Moro se ha intentado colmar con reformas en el proceso de Lisboa con sus avances y retrocesos. Sin embargo, la 
especialista en temas europeos en cuestión considera que las reformas en la Unión sólo podían realizarse modificando los Tratados fundacionales, y novedades que solo un nuevo Tratado, y no la jurisprudencia de un Tribunal, por muy innovadora que fuera (MILLÁN, 2010, p. 401-402).

A pesar de los vacíos en materia constitucional en la UE creemos que es menester señalar que en la mayoría de las constituciones de los Estados miembros (como por ejemplo la portuguesa, griega, española, alemán, u otras), existen artículos que establecen la posibilidad de transferencia de la soberanía a la Unión Europea e incluso reconocen la primacía del derecho de la Unión frente a los ordenamientos jurídicos nacionales. Además, teniendo en cuenta que las normativas comunitarias - por ejemplo, los reglamentos - tienen jerarquía superior a los ordenamientos jurídicos de los Estados y las mismas son aplicadas directamente dentro de los Estados, ellas deberán ser interpretadas y aplicadas uniformemente por los jueces nacionales. Volviendo pues al debate en torno a la temática de esta epígrafe, podríamos decir que el hecho que exista en la mayoría de las constituciones de los Estados miembros de la UE una cláusula constitucional de apertura hacia el derecho supranacional, ello puede significar la existencia de una constitución europea en cada una de las constituciones de los Estados miembros, aunque reconocemos que sea un debate todavía difícil de zanjarse.

Así, una vez hemos expuesto algunas líneas sobre las premisas básicas del nuestro artículo, hay que señalar que el modelo de control de constitucionalidad en el sistema europeo es distinto del sistema anglosajón basado en un control difuso donde cualquier ciudadano puede acudir a un Tribunal ordinario y presentar una excepción de inconstitucionalidad. Es decir, el modelo del sistema europeo es de origen austríaco y más concretamente y, más concretamente aquél planteado por el jurista Hans Kelsen. Incluso existen autores que consideran el sistema de tribunales constitucionales en Europa como un sistema “austro-kelseniano" (BON; MODERNE; RODRÍGUEZ, 1988, p. 221). Este sistema de control constitucional fue instituido por Kelsen en el año 1920 y según el jurista austríaco el control judicial de la Constitución no 
puede recaer en el Parlamento (HARO, 2004) ${ }^{1}$ ya que es el órgano donde nace la disposición normativa que presuntamente vulnera la Constitución (KELSEN, 1928, p. 221). Es decir, que el órgano legislativo (Parlamento) que crea normas que supuestamente podrían vulnerar la Constitución no puede ser el garante del control de constitucionalidad. Por ello el control de constitucionalidad en el sistema europeo se asienta en un modelo de "control concentrado" (AGUDO, 2008), es decir, que es competencia de un Tribunal especializado, normalmente el Tribunal Constitucional.

En definitiva, el sistema europeo de control de constitucionalidad/ convencionalidad nace en Austria y en Suiza con un doble objetivo: proteger los derechos fundamentales de las personas contra la acción de los poderes públicos y asegurar la regulación de los órganos y de los poderes constitucionales (SAUVÉ, 2011, p. 1).

En la línea planteada en el párrafo anterior, según Sauvé, a pesar de la uniformidad y homogeneidad apriorística, no existe un modelo común a todos los países europeos ya que el control de constitucionalidad no es "monopolistique" en las manos de una sola jurisdicción, sino un control repartido (SAUVÉ, 2011).

En este sentido, Balaguer Callejón sostiene que el Derecho constitucional europeo debe tener en consideración las realidades constitucionales de los Estados miembros, así como de los territorios infra estatales. Se trataría pues de una relación dialéctica entre el Derecho constitucional europeo y las realidades constitucionales de los Estados y territorios europeos (BALAGUER, 2013b).

Piovesan ya expuso en su trabajo sobre derecho humanos y diálogo entre jurisdicciones, el desafío del concepto constitucional convencional basado en tres aspectos: la supremacía constitucional, la primacía jurídiconormativa y el prisma estatal de los Derechos Humanos. La jurista brasileña señalaba pues en su investigación que frente a esta crisis se abre un escenario primero de diálogo entre la Constitución y los Tratados y Convenciones a los que el Estado sea parte, segundo, la apertura

\footnotetext{
${ }^{1}$ El autor expone que en el siglo XIX el control de constitucionalidad era competencia del órgano legislativo o del Parlamento.
} 
de la Constitución 'a una sociedad plural de intérpretes', y tercero, la interpretación de la Constitución desde el Human rightsapproach (PIOVESAN, 2012, p. 68-72).

En base a todo ello, simplemente creemos que debe haber concordancia en los principios y sistemas de trabajo a niveles supranacional, nacional e infra estatal a fin de garantizar la eficacia del control de convencionalidad/constitucionalidad. Como veremos un poco más adelante no siempre existe esta concordancia tanto en el sistema europeo como en los nacionales.

Señalan pues Andriantsimbazovina y Gandin (2010) que en el marco del control de constitucionalidad, las cuestiones constitucionales deben ser percibidas desde una lógica de conciliación y de ensamblaje, y no desde un sentido de oposición. En este sentido, tal como veremos en las siguientes líneas el control de convencionalidad en el sistema europeo, entre otras, significa la "fricción" entre el sistema supranacional y los sistemas internos. Así, los autores antes mencionados afirman que en este diálogo entre jurisdicciones se requiere una buena administración de relaciones. Así, en base a los principios básicos de esta buena administración de relaciones suponen la combinación entre la subsidiaridad jurisdiccional y la identidad constitucional nacional. A ellos podemos añadir, los de la responsabilidad moral y ética a nivel internacional, el respeto por los derechos humanos desde un punto de vista material y (HERRERA, 2005), tener a la condición humana como centralidad en los asuntos políticos y económicos.

En este trabajo además de preocuparnos por uno de los temas clave en el debate sobre el control de convencionalidad/constitucionalidad en la UE - la existencia o no de una Constitución europea y su relación con los sistemas nacionales de los Estados miembro - nos planteamos verificar en qué medida la jurisdicción de la Unión influye en los ordenamientos nacionales. En otras palabras, nos preguntamos ¿en qué medida el sistema de reenvío prejudicial en tanto uno de los mecanismos de control de convencionalidad/constitucionalidad, influye en políticas de vivienda y migratorias en España? 
Para la elaboración del presente artículo tuvimos como metodologías de trabajo, en primer lugar, la revisión bibliográfica sobre la UE y la complejidad de su sistema de control de constitucionalidad/ convencionalidad y, en segundo lugar, el análisis de jurisprudencias europeas y españolas sobre el reenvío prejudicial, así como artículos y comentarios al respecto.

En base a lo expuesto en la hipótesis planteada en el párrafo anterior, en un primer momento presentamos la estructura del control de constitucionalidad/convencionalidad en el sistema europeo, para después exponer y analizar la aplicación del mecanismo específico de reenvío prejudicial en dos casos concretos, el caso Mohamed Aziz vs. CatalunyaCaixa y los casos N. D. contra España y N.T. contra España.

\section{Estructura del Control de Constitucionalidad/ Convencionalidad en el Sistema Europeo}

Tras haber abordado brevemente algunas cuestiones clave sobre el control de constitucionalidad/convencionalidad en el sistema europeo, en las siguientes líneas trataremos de exponer su proceso de funcionamiento en el seno institucional tanto de la Unión Europea como de algunos de sus Estados miembros.

Pero antes creemos que es relevante señalar que el principio de separación de poderes en el seno de la Unión Europea es, por lo menos, de su propio género o especie, parafraseando a Martínez Estay. Éste, señala que el único poder que cuenta con características convencionales y clásicas es el judicial, representado a través del Tribunal de Justicia de la Unión Europea (MARTÍNEZ, 2005, p. 65). Con ello pretendemos afirmar que la relación de poderes legislativo, ejecutivo y judicial no es ni similar a la de los Estados miembros, ni cuentan con características convencionales.

El control de constitucionalidad en el sistema europeo es tarea de dos instituciones judiciales en conjunto con las entidades judiciales nacionales de los Estados miembros, siendo el Tribunal de Justicia de la 
Unión Europea la encarnación del poder judicial, y la Corte Europea de Derechos Humanos lavigilante del cumplimiento u omisiones por parte de los Estados del Convenio Europeo de los Derechos Humanos. Antes plantearemos de forma sucinta el sistema de funcionamiento de la Corte Europea de los Derechos Humanos para después entrar en profundidad con el sistema del Tribunal de Justicia, alcual consideramos más relevante y vinculante en sus decisiones de cara a los Estados miembros europeos.

\subsection{Corte Europea de los Derechos Humanos}

La Corte Europea de los Derechos Humanos fue creada el 5 de mayo de 1959 y es competente para recibir quejas tanto individuales como interestatales que aleguen vulneraciones de los derechos civiles y políticos establecidos en la Convención Europea de los Derechos Humanos. Según datos de la propia Corte, desde su creación sólo ha habido denuncias de vulneraciones interpuestas por grupos de individuos u ONGs.

De acuerdo con los criterios de admisibilidad de la Corte, las denuncias individuales deben haber agotado antes los recursos judiciales internos. La función de la Corte es pues la de contrarrestar la acción de los Estados y atacar la omisión del legislador nacional en la aplicación de la Convención Europea de los Derechos Humanos (SAGUÉS, 2011).

El Tribunal está compuesto por el mismo número de Estados parte, es decir, actualmente cuarenta y siete. Los jueces son elegidos por la Asamblea Parlamentaria del Consejo de Europa a partir de la propuesta de tres candidatos hechas por cada Estado. A pesar que desde la propia Corte se garantice la independencia de los jueces del Tribunal, en parte es evidente que su nombramiento por los Estados juega un papel muy importante en sus decisiones en la Corte.

Aunque las decisiones de la Corte no son tan vinculantes como el Tribunal de Justicia de la Unión Europea, algunas han influido en los países miembros que vulneraron el derecho de la Convención a cambiar su legislación y prácticas administrativas en varios ámbitos. En este trabajo verificaremos y analizaremos una Resolución del Tribunal en cuestión en la que se pide explicaciones al Estado español sobre las 
devoluciones en caliente, ya que no solamente vulnera la Ley Orgánica de Extranjería sino igualmente la Convención Europea de los Derechos Humanos y otras normativas nacionales e internacionales.

Tal como veremos en el siguiente apartado, a diferencia del Tribunal de Justicia de la Unión Europea, la Corte Europea practica el control de constitucionalidad por sí mismo, pero no exige a los jueces nacionales que dejen de aplicar el derecho local contrario a la Convención Europea de Derechos Humanos (SAGUÉS, 2011, p. 415). También es evidente que el control de convencionalidad no es solamente el de verificar la adecuación del derecho interno a la Convención Europea de Derechos Humanos, sino igualmente de acuerdo con la jurisprudencia del Tribunal Europeo de Derechos Humanos (SAGUÉS, 2011, p. 415).

Como podemos ver la Corte Europea de Derechos Humanos no ejerce una acción de constitucionalidad que conlleve un cambio profundo en las legislaciones nacionales de los Estados. La entidad cuya jurisprudencia y acción son más vinculantes en la materia es el Tribunal de Justicia de la Unión Europea.

\subsection{Tribunal de Justicia de la Unión Europea}

El Tribunal de Justicia de la Unión Europea (en adelante TJUE) fue instituido en el año 1952 y tiene como objetivos: velar por el cumplimiento 'unánime' de la legislación europea por parte de los Estados miembros y resolver litigios entre los gobiernos nacionales y las instituciones europeas.

El Tribunal consta de tres órganos según la página web de la Unión Europea, a saber: Tribunal de Justicia, Tribunal General y el Tribunal de la Función Pública. El Tribunal de Justicia resuelve las cuestiones prejudiciales planteadas por los tribunales nacionales, ciertos recursos de anulación y los recursos de casación; el Tribunal General resuelve los recursos de anulación que interponen los particulares, las empresas y, en algunos casos, los gobiernos nacionales; y el Tribunal de la Función 
Pública resuelve los litigios entre la Unión Europea y su personal ${ }^{2}$. Como se observa hemos hecho referencia, entre otras, a 'cuestiones prejudiciales' y los 'recursos de anulación y de casación', éstos últimos algunos de los mecanismos de control constitucional del TJUE tanto a las instituciones europeas como a las nacionales. Más adelante ahondaremos en estas cuestiones.

Antes queremos hacer referencia a algunos casos que marcaron ciertos principios de actuación del TJUE. En primer lugar está el caso Van Gen en Loos de 1963 que marcó la aplicación del principio de efecto directo el cual permite a los nacionales de los Estados miembros invocar un derecho comunitario ante un juez nacional. En segundo lugar se encuentra el caso Costa c. ENEL del año 1964 que estableció la primacía del derecho de la Unión Europea sobre la legislación de sus Estados miembros. Y en tercero y último lugar se encuentra el caso Administration des financesitaliennes c. Simmenthaldel año 1978. En este último existen por lo menos dos cuestiones importantes, por un lado, se deja patente y evidente que el derecho interno no impide la aplicación del derecho comunitario y, por otro, para aplicar el derecho comunitario por parte de los jueces nacionales no es necesario que la norma interna sea derogada (SAGÜÉS, 2011). Debido a las circunstancias de crisis económica, de valores y principios democráticos y sociales, algunos de estos principios no son igualmente contundentes cuando de las sentencias aquí mencionadas. A título de ejemplo, señala Millán Moro que el principio de primacía del derecho comunitario desaparece del Tratado de Lisboa y queda simplemente mencionado en la Declaración relativa a la primacía como uno de los pilares fundamentales de la Unión (MILLÁN, 2010, p. 402).

Como adelantamos antes, el TJUE en tanto el auténtico Tribunal Constitucional que tutela la Constitución no codificada de la Unión Europea (MARTÍNEZ, 2005) tiene ciertos mecanismos de control de constitucionalidad/convencionalidad. En este sentido podemos señalar como los más importantes el recurso por incumplimiento; los sistemas de

\footnotetext{
${ }^{2}$ Informação disponível em: http://europa.eu/about-eu/institutions-bodies/court-justice/ index_es.htm. Acesso em: 20 jul. 2015,
} 
control de legalidad comunitaria; la cuestión prejudicial; y el control por vía consultiva. Trataremos de explicar algunos de los más relevantes.

De acuerdo con la página jurídica de la Unión Europea (EUR-Lex), el recurso por incumplimiento es un procedimiento jurisdiccional que se ejerce ante el Tribunal de Justicia de la Unión Europea. La Comisión Europea o un Estado miembro pueden interponer este recurso contra un Estado miembro ${ }^{3}$ que no haya respetado el Derecho de la Unión Europea. El recurso en cuestión se fundamenta en los artículos 258 y 260 del Tratado de Funcionamiento de la Unión Europea (TFUE).

El incumplimiento al que hace referencia el recurso en cuestión puede producirse por medio de actos (leyes, decretos, decisiones administrativas, entre otras) o de hechos (p. ej. prácticas administrativas). Puede ser igualmente consecuencia de comportamientos positivos (acciones) o negativos (abstenciones u omisiones). Un ejemplo de lo primero podría ser la adopción de un texto contrario al Derecho de la Unión Europea o la negativa explícita a levantar una medida interna contraria. Las abstenciones u omisiones podrían consistir por ejemplo, en retrasos en la transposición de una Directiva o en la no comunicación de las medidas nacionales de ejecución a la Comisión por parte de los Estados miembros ${ }^{4}$.

Los sistemas de control de la legalidad comunitaria pueden ser ejercidos a través de los recursos de anulación, recurso por omisión y la excepción de ilegalidad.

Mediante el recurso de anulación (arts. 263 y 264 TFUE) el demandante, que pueden ser instituciones europeas o particulares bajo ciertas condiciones, solicita la anulación de un acto adoptado por una institución, un órgano o un organismo de la Unión Europea. El recurso en cuestión puede ser ejercido en contra de todos los actos legislativos; actos adoptados por el Consejo, la Comisión, el Banco Central Europeo (BCE), el Parlamento Europeo y el Consejo Europeo, si dichos actos están

${ }^{3}$ Entiéndase por Estado miembro en sentido lato, siendo cualquiera de sus órganos: Gobierno, Parlamento, entidades federadas, corporaciones infra estatales, entre otras.

${ }^{4}$ Informação disponível em: http://eur-lex.europa.eu/legal-content/ES/TXT/HTML/?uri= URISERV:114550\&from=ES. Acesso em: 20 jul. 2015. 
destinados a producir efectos jurídicos sobre terceros; actos adoptados por órganos u organismos europeos si dichos actos están destinados a producir efectos jurídicos sobre terceros; y deliberaciones del Consejo de los gobiernos o del Consejo de Administraciones del Banco Europeo de Inversiones (BEI) en las condiciones del art. 271 del TFUE.

El recurso por omisión establecido en el art. 265 y 266 TFUE regula que en caso de violación del presente Tratado y el Parlamento Europeo, el Consejo o la Comisión se abstengan de pronunciarse, los Estados miembros y las demás instituciones de la Comunidad podrán recurrir al Tribunal de Justicia con objeto de que se declare dicha violación (GOMES, 2012, p. 105).

Dejamos para el último lugar a fin de desarrollarla con más detenimiento la cuestión o reenvío prejudicial ya que creemos que encarna el aspecto integral de control de constitucionalidad, una vez implica tanto al TJUE como a los jueces nacionales de los Estados miembros.

Según Gomes y Winter el reenvío es el mecanismo prejudicial que permite la cooperación judicial entre la instancia supranacional y la de los Estados miembros (GOMES; WINTER, 2014, p. 185-186). En este sentido, señala Peláez que a través de las cuestiones prejudiciales el juez nacional realiza, en colaboración con el juez comunitario, una función que se les atribuye en común y que tiene por objeto asegurar el respeto del derecho en la aplicación y la interpretación de los tratados (PELÁEZ, 2000, p. 102).

Señala Gomes que en las instancias judiciales ordinarias la aceptación de la cuestión prejudicial por parte del juez nacional no es obligatoria, sin embargo, en las extraordinarias y en aquellas instancias judiciales que no admiten recursos la cuestión prejudicial sí es obligatoria, teniendo siempre en cuenta que no se haya planteado la cuestión anteriormente en una instancia ordinaria (GOMES, 2012, p. 107-108).

El reenvío prejudicial se regula de acuerdo con lo establecido en el art. 267 TFUE y los artículos I-29. 3b y III. 358.3 de la Constitución de la UE. Martínez Estay en su trabajo sobre el sistema europeo continental de justicia constitucional afirma que la cuestión prejudicial sólo puede 
ser requerida por órganos jurisdiccionales y, que las partes en el proceso pueden sugerírselo al juez pero no tienen derecho de formulación (MARTÍNEZ, 2005, p. 78).

Es menester señalar que la cuestión prejudicial planteada $\mathrm{y}$ sentenciada por el TJUE afecta a todos los órganos jurisdiccionales de los Estados miembros (MARTÍNEZ, 2005). En el siguiente apartado expondremos un caso práctico sobre la cuestión prejudicial en España en materia hipotecaria.

Como ya hemos adelantado en párrafos anteriores el control de constitucionalidad/convencionalidad en la Unión Europea no es sólo tarea del Tribunal Europeo de los Derechos Humanos y del Tribunal de Justicia de la Unión Europea, sino igualmente de los jueces nacionales. Es en este último ámbito donde existen ciertas discrepancias, mostrando así conflictos entre los principios de subsidiariedad jurisdiccional y la identidad constitucional nacional señalados anteriormente.

Fieles al modelo austro-kelseniano la mayoría de países europeos, con excepción de Alemania, tiene la regulación de la función jurisdiccional de control de constitucionalidad separada de la función jurisdiccional ordinaria. Así, por ejemplo en España, el Tribunal Constitucional que realiza a nivel interno el control de constitucionalidad está separado, desde el punto de vista reglamentario, del Poder Judicial que es un órgano de la Administración del Estado.

En Alemania la regulación del Tribunal Constitucional se encuentra en el marco del Poder Judicial y más concretamente en la Sección IX de la Ley Fundamental (AGUDO, 2008). En las siguientes líneas trataremos de exponer brevemente los contextos legislativos de cuatro países europeos en relación a la recepción del derecho internacional y supranacional.

En Francia, en principio, el control de constitucionalidad y de convencionalidad tienen naturalezas diferentes, ya que la Constitución tiene el carácter de "absoluta y definitiva" ante las leyes y, los tratados y convenciones tienen jerarquía "relativa y contingente" ante las leyes. Sin embargo, el art. 55 de la Constitución francesa reconoce la superioridad de los tratados y acuerdos regularmente ratificados y aprobados sobre 
las leyes nacionales (SAGUÉS, 2011). Esta controversia es lo que Bruce considera 'competencia jurisdiccional bipartita' (BRUCE, 2010).

En España desde el año 2004 tras el Dictamen del Tribunal Constitucional, en principio, no existe incompatibilidad entre el Tratado Constitucional de la UE y la Constitución Española (CE) (MILLÁN, 2010). Sin embargo, una de las dificultades para entrever el control de convencionalidad en el contexto español es que el principio de primacía de los tratados no se encuentra "expresa y claramente enunciado por la Constitución (arts. 95 y $96 \mathrm{CE}$ ), ni totalmente aceptada la jurisprudencia y la doctrina del país [...] aunque en ciertos Tribunales Superiores de Justicia y Salas de lo Contencioso se hable del principio de "supralegalidad" de los Convenios internacionales que no significa “supraconstitucionalidad” (SAGUÉS, 2011, p. 408-409).

A lo ya señalado en el marco español se añaden dificultades incluso para realizar el control de convencionalidad "desde abajo" por los jueces ordinarios, entre otras cuestiones, por la falta de formación universitaria en la materia y las contradicciones entre el Tribunal de Justicia de la Unión Europea y el Tribunal Europeo de Derechos Humanos, aunque ésta última cuestión puede resolverse invocando la pauta judicial más protectora de la persona (SAGUÉS, 2011, p. 408-409).

En Alemania el debate es más contundente ya que se argumenta que una estructura supranacional "no puede suponer un ataque" a las estructuras constitucionales internas, recurriendo así a la reserva constitucional.

En Italia el derecho interno sigue lo establecido por el caso Semmenthal mencionado al inicio de este trabajo y, de esta forma la Corte Constitucional declara inconstitucionales todas aquellas leyes nacionales contrarias al Derecho comunitario.

Uno de los debates candentes en Italia en la materia es el de si los jueces comunes pueden o no realizar el control de convencionalidad o, si es única y exclusivamente una labor de la Corte Constitucional. 


\section{Práctica del Control de Convencionalidad por los Órganos Europeos}

En este apartado haremos referencia a dos casos prácticos en los que se vislumbra el ejercicio del control de convencionalidad tanto por la Corte Europea de los Derechos Humanos como por el Tribunal de Justicia de la Unión Europea. Aquí nos centraremos en el control realizado por estas dos instituciones al Estado español.

\subsection{La Cuestión Prejudicial en España: el caso Mohamed Aziz V. CatalunyaCaixa}

Con base en todo lo aquí expuesto sobre las cuestiones prejudiciales, en las siguientes líneas expondremos un caso dado en España en el que el juez nacional aplicó la cuestión prejudicial a efectos de consultar al juez comunitario sobre la materia hipotecaria.

Antes de entrar en detalles sobre el caso en cuestión creemos que es imprescindible realizar una cierta contextualización en cuanto a la crisis económica en España y el derecho a la vivienda.

El derecho a la vivienda en España está garantizado para todos los españoles y españolas en los términos establecidos en el art. 47 de la CE y, en el caso de los extranjeros extracomunitarios, el art. 13 de la Ley Orgánica de Extranjería 4/2000 que establece el acceso a las ayudas sociales en materia de vivienda a los extranjeros residentes, es decir, en situación de regularidad administrativa, una suerte de 'estratificación cívica' entre los migrantes (TOMÉ, 2015, p. 100).

Sin embargo, dada la crisis económica y financiera que asoló el sistema global desde el año 2007, hoy asistimos en España a una subordinación de los derechos sociales en el cumplimiento del pagamento de la deuda, por lo que la efectividad de ésos se queda en entredicho. Muestra de ello fue la reforma del art. 135 de la CE realizada con los apoyos del Partido Popular y el Partido Socialista de España en el año 2011. 
Así es como desde el inicio de la crisis (años 2007-2008) se realizaron en España más de 400.000 ejecuciones hipotecarias y, una gran parte acabó en desahucio, es decir, familias que fueron expulsadas de sus casas por el impago de las hipotecas.

Aunándose a la crisis económica está el hecho cultural de desigualdades tanto en materia de propiedad, como en el contrato entre una persona jurídica y un individuo. En este sentido, en España se viene avistando desde hace varios años la incorporación de cláusulas suelo ${ }^{5}$ en los contratos hipotecarios que son claramente abusivos como veremos más adelante.

El origen jurídico del caso Mohamed Aziz v. CatalunyaCaixa (Asunto C-415/11) es el planteamiento de la cuestión prejudicial realizada por el Juzgado de lo Mercantil n 3 de Barcelona el 19 de julio de 2011 al amparo del art. 267 del TFUE, sobre la interpretación de la Directiva 93/13/CEE del Consejo de 5 de abril sobre cláusulas abusivas en los contratos celebrados con los consumidores (SERRATS, 2015, p. 688).

El procedimiento en realidad empieza el 19 de julio de 2007 cuando el Sr. Aziz suscribe con CatalunyaCaixa un contrato con garantía hipotecaria siendo el inmueble su vivienda habitual. El capital prestado al Sr. Aziz para la adquisición de la vivienda fue de $138.000 €$ a ser amortizado en 33 mensualidades con 396 cuotas mensuales a partir del $1^{\text {o }}$ de agosto de 2007 (SERRATS, 2015, p. 688).

Desde junio de 2007 hasta mayo de 2008 el Sr. Aziz pagaba con regularidad todas sus cuotas hipotecarias, dejando de hacerlo en esta fecha debido a, como expusimos antes, la crisis económica que lo conllevó a la pérdida del empleo y, por consiguiente, la falta de medios económicos, así como les pasó a muchas familias en España. En este sentido, "CatalunyaCaixa ante la falta de pago, acudió a un notario para el otorgamiento del acta de determinación de la deuda. Posteriormente, tras requerir infructuosamente el pago de lo debido al Sr. Aziz, inició un

\footnotetext{
${ }^{5}$ Se trata de una cláusula que establece un mínimo a pagar en las cuotas de la hipoteca aunque los intereses ordinarios que se han acordado con la entidad financiera (ej. EURIBOR) estén por debajo.
} 
procedimiento de ejecución hipotecaria contra el mismo el 11 de marzo de 2009 (SERRATS, 2015, p. 688-689).

Dada las incomparecencias del Sr. Aziz en los Juzgados y no habiendo realizado alegaciones a los hechos expuestos por CatalunyaCaixa, en julio de 2010 se celebró subasta judicial para proceder a la venta del inmueble. No habiéndose presentado ninguna oferta y, conforme a lo previsto en la Ley de Enjuiciamiento Civil (LEC), CatalunyaCaixa se adjudicó el inmueble por el $50 \%$ de su valor (SERRATS, 2015, p. 688). La adjudicación de la vivienda, aunque está conforme a la legislación, por un valor inferior al reclamado al cliente muestra las desigualdades y las atrocidades en el sistema de adquisición de viviendas en España.

Tras la adjudicación de la vivienda el Juzgado fijó la trasmisión de la posesión el día 20 de enero de 2011 expulsando al Sr. Aziz de su vivienda. Así, el día 11 de enero de 2011 el Sr. Aziz presentó demanda de proceso declarativa solicitando la anulación de la cláusula 15 del contrato de préstamo hipotecario por considerarla abusiva y, consecuentemente la anulación del procedimiento de ejecución, es decir, del desahucio (ibídem).

El Juzgado de lo Mercantil donde se interpuso la demanda manifestó dudas en cuanto a la conformidad del Derecho español con el marco jurídico establecido por la Directiva 93/13/CEE y, suspendió el procedimiento y planteó al Tribunal de Justicia de la UE, si lo establecido en el art. 695 LEC limita la tutela del consumidor y si la determinación de los elementos constitutivos de la "cláusula abusiva" a fin de determinar si tienen carácter abusivo las cláusulas del contrato realizado entre el Sr. Aziz y CatalunyaCaixa (SERRATS, 2015, p. 690).

Ante la cuestión prejudicial planteada por el Juzgado de lo Mercantil $n^{\circ} 3$ de Barcelona, el TJUE respondió en primer lugar que la Directiva 93/13/CEE debe ser interpretada en el sentido que se opone a una normativa de un Estado miembro como la controvertida en el litigio principal, y en segundo lugar que no tiene competencias para pronunciarse sobre el carácter abusivo o no de las cláusulas del contrato objeto del litigio principal (SERRATS, 2015, p. 690). 
El pronunciamiento del TJUE en la materia generó una reforma legislativa en el marco español y la creación de la Ley 1/2013, de 14 de mayo, de medidas para reforzar la protección a los deudores hipotecarios, reestructuración de la deuda y alquiler social. Sobre la reforma realizada señala Serrats que "[...] el legislador ha optado por modificar el art. 695 LEC y dejar inalterado el art. 698 LEC [...]" (SERRATS, 2015, p. 699), dos articulados polémicos de la LEC en materia hipotecaria y contractual.

Serrat añade además que cabe avanzar que la Ley 1/2013, de 14 de mayo, está acorde con la Directiva 93/13/CEE puesto que da preferencia a la protección del deudor y a la no vinculación de las cláusulas frente al acreedor hipotecario y a la rapidez del procedimiento (SERRATS, 2015, p. 690).

En el siguiente apartado expondremos comentarios sobre la solicitud de explicaciones del Tribunal Europeo de Derechos Humanos al Estado español en materia de devoluciones en caliente tal como adelantamos antes.

\subsection{Caso N. D. Contra España y N. T. Contra España}

Antes de argumentar sobre los casos presentados en el encabezado de este apartado, permítanos realizar una pequeña contextualización de las devoluciones en caliente en España.

Desde el establecimiento de visados en los años ochenta para la entrada en el territorio Schengen, las fronteras de Ceuta y Melilla (aún sin ser territorio Schengen) son los territorios de retención y llegada de inmigrantes, debido principalmente a ser la puerta de entrada entre el continente africano y europeo. Por este motivo estas fronteras también son desde el antaño, espacios de devolución de inmigrantes del territorio español al territorio marroquí vecino. Las devoluciones consisten en que cuando un inmigrante habiendo superado las vallas de dos y seis metros y accedido al territorio español, éste es automáticamente devuelto por el Agente de la Guardia Civil española al territorio marroquí. Estas prácticas que hasta el año 2015 se realizaban sin amparo jurídico alguno, vulneraban, entre otras, la Constitución Española (arts. 9; 103; y 106) la propia Ley de Extranjería española (arts. 31; 58.3) y su Reglamento (art. 
23), la Ley 12/2009 española de asilo, de 30 de octubre (arts. 3 y 10), el Acuerdo entre España y Marruecos sobre la repatriación de extranjeros de 13 de febrero de 1992, la Carta de los Derechos Fundamentales de la Unión Europea (arts. 18; 19.1; y 19.2) y la Convención de Viena sobre refugiados de 1951 y su Protocolo de 1967.

Incluso hoy día tras su legalización a través de la Ley Orgánica 4/2015 de 30 de marzo, de Protección de la Seguridad Ciudadana, se siguen vulnerando, entre otras, las normativas señaladas en el párrafo anterior y, además, según un grupo de juristas españoles, se ha cometido en el proceso de aprobación de esta Ley un uso abusivo de enmiendas (STC 119/2011, de 15 de julio).

Otra cuestión de vulneración que cabe señalar en esta Ley es el delito de prevaricación que cometería (y están cometiendo) los agentes de autoridad fronteriza, previsto en el art. 404 del Código Penal español ${ }^{6}$.

Tras haber realizado una muy breve contextualización de las expulsiones en caliente y las vulneraciones que esta práctica supone, en las siguientes líneas trataremos de exponer las circunstancias de los casos que nos conciernen.

Las demandas contra España fueron presentadas por N. D. de nacionalidad maliense, representado por el Abogado Me. G. Boye Tuset (Madrid) y N. T. de nacionalidad marfileño representado por el Abogado Me. G. Gericke (Hamburgo). Las circunstancias presentadas por el ciudadano maliense fueron que huyó de su tierra en el año 2012 debido al conflicto armado que asola el país desde enero de 2012. Incluso tras la firma del Acuerdo de paz en el año 2013 hubo serias situaciones de precariedad de condiciones humanas en Malí. En el año 2013 el ciudadano maliense en cuestión llegó a Marruecos donde, al igual que

\footnotetext{
${ }^{6}$ A fin de profundizar sobre las vulneraciones de las normativas nacionales, regionales (UE) e internacionales cometidas en la Ley Orgánica 4/2015, así como en incoherencias en el uso de ciertas expresiones y medidas, consulte "Expulsiones en caliente: cuando el Estado actúa al margen de la Ley (2014)" y "Rechazos en frontera": ¿frontera sin derecho? (2015)", ambos del proyecto DER 2011 - 26449.
} 
otros migrantes en Marruecos, vivió en condiciones infrahumanas en el Monte Gourougou, cerca de la frontera melillense ${ }^{7}$.

Las circunstancias presentadas por el ciudadano marfileño son similares a las del maliense teniendo en cuenta los conflictos armados que iniciaron en Costa de Marfil desde los años noventa y no han cesado del todo hasta nuestros días, a pesar de varios procesos de Acuerdos de paz. El ciudadano marfileño llegó a Marruecos a fines de 2012 y también vivió en condiciones infrahumanas en el Monte Gourougou.

El día 13 de agosto de 2014 ambos intentaron, junto a otros inmigrantes negro africanos, entrar en el territorio español a través del puesto fronterizo de Melilla. En este intento fueron agredidos por los agentes marroquíes y españoles. Cuando lograron saltar la tercera valla y llegar al territorio español en Melilla, fueron esposados y devueltos al territorio marroquí, sin haber hecho ninguna entrevista, sin haber prestado declaración sobre sus respectivas situaciones personales, sin atención jurídica ni intérprete. En Marruecos fueron llevados a la Comisaría de Nador (Marruecos) y posteriormente dejados a su suerte, junto a otros migrantes negro africanos, en la provincia de Fes (Marruecos) a $300 \mathrm{~km}$. de Nador.

En diciembre volvieron a intentar la entrada al territorio español por la valla de Melilla y en esta ocasión el ciudadano maliense fue devuelto a su país de origen y al marfileño se le incoó una orden de expulsión ${ }^{8}$.

Tal como dijimos antes, la práctica de devolución en frontera que hemos comentado anteriormente y que se realizaba sin ninguna legitimidad jurídica fue ratificada en el año 2015 a través de la Ley Orgánica 4/2015, de 30 de marzo, modificando así la Ley Orgánica 4/2000 de 11 de enero, sobre derechos y libertades de los extranjeros en España y su integración social. En la Disposición Adicional Final primera de la Ley Orgánica 4/2015, de 30 de marzo se añade una Disposición

\footnotetext{
${ }^{7}$ El Monte Gourougou se encuentra en el territorio marroquí cerca de la frontera con la ciudad autónoma de Melilla (España).

${ }^{8}$ Incoar una orden de expulsión a un inmigrante significa que la Policía Nacional le remite una notificación dándole un plazo de 15 días para dejar el territorio español.
} 
Adicional Décima a la Ley Orgánica 4/2000, de 11 de enero con el siguiente contenido:

1. Los extranjeros que sean detectados en la línea fronteriza de la demarcación territorial de Ceuta y Melilla mientras intentan superar los elementos de contención fronterizos para cruzar irregularmente la frontera podrán ser rechazados a fin de impedir su entrada ilegal en España.

2. En todo caso, el rechazo se realizará respetando la normativa internacional de derechos humanos y de protección internacional de la que España es parte.

3. Las solicitudes de protección internacional se formalizarán en los lugares habilitados al efecto en los pasos fronterizos y se tramitarán conforme a lo establecido en la normativa en materia de protección internacional. (LEY N. 4, DE 11 DE ENERO DE 2000)

Tal como ya expusimos anteriormente, por más que los articulados aquí señalados intenten presentar una normativa respetuosa con la normativa internacional, solo su planteamiento ya incumple con normativas nacionales, regionales e internacionales.

Las circunstancias sufridas por los inmigrantes demandantes al Estado español ya fueron anteriormente denunciadas por los Observadores del Comité contra la Tortura de la ONU en su visita a España en julio de 2014. Los Observadores en cuestión mostraban su preocupación tanto por las condiciones de trato a los inmigrantes en las fronteras, como en los Centros de Internamiento de Inmigrantes (CIE) de Barcelona y de Madrid. Igualmente mostraban su preocupación con el entonces proyecto de Ley del gobierno que visaba la devolución inmediata de los inmigrantes al territorio marroquí.

No solamente los Observadores del Comité contra la tortura criticaban la situación de trato deshumano a los inmigrantes en España sino igualmente el ACNUR. Ésta última en octubre de 2014 realizó una rueda de prensa en la que manifestaba que debe prevalecer en las fronteras españolas de Ceuta y Melilla el respeto a los derechos humanos y a la 
dignidad humana de los inmigrantes y, permitir la atención a aquellos que requieran protección internacional.

Los demandantes antes mencionados invocaron los artículos 3 y 13 de la Convención de Derechos Humanos reclamando así la devolución inmediata sin tener en cuenta los tratos que sufrirían de las manos de los agentes marroquíes. Igualmente invocaron el art. 4 del Protocolo n. 4 en relación a la política de devolución sistemática sin base jurídica, desprovista de toda asistencia jurídica e intérprete y examen de casos individuales. Y finalmente invocaron el art. 13 de la Convención en relación al art. 4 del Protocolo n. 4 sobre la posibilidad de prestar declaración de sus respetivas situaciones personales a las autoridades españolas competentes y a presentar recursos ante las entidades judiciales españolas competentes.

La Corte a pesar de todo lo expuesto por las partes demandantes no reconoce vulneración ninguna de la Convención de Derechos Humanos por parte del Estado español.

En relación a la expulsión inmediata sin posibilidad de realizar declaración ante las entidades españolas competentes y a presentar recursos ante entidades judiciales españolas competentes, la Corte no se pronuncia, reenviando el caso al Estado español para que se explique de conformidad con el art. $54 \S 2$ b de su Reglamento.

\section{Conclusión}

En el presente trabajo hemos intentando realizar una síntesis del control de constitucionalidad/convencionalidad en el sistema europeo. Por europeo no nos referimos a los países pertenecientes al Consejo de Europa sino al sistema regional de la Unión Europea.

Respondiendo a la hipótesis planteada al inicio de este trabajo, nosotros consideramos que ante todo habría que asegurar un marco constitucional efectivo y coercitivo antes de plantear su influencia en las políticas en materia de vivienda y migración en España. Hemos podido 
ver, en base a los análisis realizados en este trabajo, que aunque muchos autores se empeñen en defender una Constitución europea, ésta última es el ensamblaje de las Constituciones nacionales de los Estados miembro y, por ello la casi inexistencia de la misma. Ocurre que el sistema europeo actual se construyó y, se sigue construyendo, en base a la transferencia de las prerrogativas tradicionales y convencionales de los Estados miembro (de forma desigual entre los Estados) haciendo que se repitan los mismos dilemas convencionales que se dan a nivel nacional. Es por ello que creemos que se requiere un cambio de modelo en el sistema europeo y su supuesto marco constitucional a pesar de reconocer sus avances, en esta materia, frente a otros bloques regionales.

El modelo de control de constitucionalidad europeo fundamentado y basado en el modelo austro-kelseniano, y de característica concentrada a diferencia del anglosajón que es difuso, tiene ciertas debilidades desde nuestro punto de vista. Es decir, la declaración de inconstitucionalidad de una normativa o una práctica administrativa es competencia de una sola entidad, el Tribunal Constitucional, al que la mayoría de los ciudadanos y ciudadanas tienen la imposibilidad e incapacidad de acceder. Creemos, pues, que ello hace que prevalezcan varias prácticas inconstitucionales. A ello se añade la composición del Tribunal en ciertos países europeos que hace que sus declaraciones estén exentas de neutralidad.

No existe a nivel de la U.E un único modelo de control de constitucionalidad/convencionalidad sino que se trata más bien de un ensamblaje, una conciliación, un diálogo entre jurisdicciones nacionales y el sistema regional europeo. En otras palabras, la combinación entre la subsidiaridad jurisdiccional y la identidad constitucional nacional. Tal como hemos visto en este trabajo esta combinación no siempre se da ya que incluso el principio de primacía del derecho comunitario que prevaleció en el caso Costa vs. ENEL, en la última reforma del Tratado de la U.E en el año 2009, se quedó reducida a una Declaración separada del Tratado.

De las dos estructuras que constituyen el marco del control de constitucionalidad/convencionalidad de la U.E podemos deducir que el 
TJUE es el que ejerce mayor influencia ante los contextos nacionales de los Estados miembros. Así, a través de sus mecanismos de control y más concretamente, a través de la cuestión prejudicial se llega a replantear la adecuación de la normativa nacional con el marco legislativo comunitario como se dio en el caso Mohamed Aziz vs. CatalunyaCaixa.

Creemos que el motivo de debilidad de la Corte Europea de los Derechos Humanos es justo este diálogo con la identidad constitucional nacional. Como hemos visto en el caso expuesto en este trabajo (N.T. y N.D contra España), a pesar de las vulneraciones de las legislaciones nacionales, regionales e internacionales relatados por los demandantes, podríamos decir que el Tribunal no se atrevió a pronunciarse al respeto pidiendo explicaciones al Estado español.

Concluimos pues que habría que añadir como sistemas de garantía en materia del control de convencionalidad/constitucionalidad en el sistema europeo, la cuestión de la coherencia o divergencia en las políticas entre la UE y los Estados miembro, así como el proceso de lucha que se lleve a cabo en un Estado europeo determinado frente al derecho reclamado. Es decir, por un lado no solamente se trata de un control a fin de verificar el incumplimiento por parte del Estado español de las cláusulas abusivas en materia hipotecaria, sino la presión social y política que ejerció, entre otras, la Plataforma de Afectados por la Hipoteca (PAH) impulsando así la acción del Juez de lo Mercantil, la sensibilidad del Tribunal de Justicia de la UE y ciertos cambios en el marco normativo español. Por otro lado, vemos que frente a la coherencia de las políticas migratorias entre las instituciones europeas y los Estados miembro, a pesar de la evidente vulneración de los derechos de las personas migrantes y, cláusulas, entre otras, del Convenio europeo de Derechos Humanos y Libertades fundamentales, la institución europea encargada de realizar el control de convencionalidad en los casos analizados en esteartículo no se dignó a pronunciarse al respecto, reenviando el caso al ámbito nacional del Estado que ha incumplido las normas. 


\section{Referencias}

ACUERDO ENTRE ESPAÑA Y MARRUECOS sobre la repatriación de extranjeros de 13 de febrero de 1992.

ADMINISTRATION des financesitaliennes c. Simmenthal, ECLI: EU: C: 1978: 49 (1978)

AGUDO ZAMORA, Miguel. El modelo institucional europeo de justicia constitucional. In: ACTAS DEL V CONGRESO DE LA ASOCIACIÓN DE CONSTITUCIONALISTAS DE ESPAÑA. Valencia: Ed. Tirant Lo Blanch, 2008.

ANDRIANTSIMBAZOVINA, Joël; GANDIN, Hélène. Contrôle de constitutionalité des lois constitutionnelles et droit européen - la conviction d'une piste à emprunter. Nouveau Cahiers du Conseil, [S.l.], n. 27, p. 1-8, 2010.

BALAGUER CALLEJÓN, Francisco. Perfis metodológicos do direito constitucional europeu. In: PEREIRA DA SILVA, Vasco; BALAGUER CALLEJÓN, Francisco (ed.). O constitucionalismo no século XXI na sua dimensão estadual, supranacional e global. Lisboa: Instituto de Ciências Jurídicas e Políticas, 2015. p. 61-83.

BALAGUER CALLEJON, Francisco. Crisis económica y crisis constitucional en Europa. Revista Española de Derecho Constitucional, [S.l.], n. 98, mayo-agosto, p. 91-107, 2013.

\section{BIACCHI GOMES, Eduardo. Manual de Direito da Integração}

Regional. 2. ed. Curitiba: Ed. Juruá, 2012.

BIACCHI GOMES, Eduardo; CARTA WINTER, Luis Alexandre. Os mecanismos do Tribunal de Justiça da União Europeia e a proteção dos Direitos Fundamentais. In: XAVIER BAEZ, Narciso L. et al. (org.). Mecanismos internacionais e internos de efectividade dos Direitos fundamentais. Santa Catarina: Joaçaba; Ed. UNOESC, 2014. p. 181196.

BON, P.; MODERNE, F.; RODRIGUEZ, Y. La garantie constitutionnelle de la Constitution. Revue de Droit, [S.l.], 1988. 
BRUCE, Eva. Contrôle de constitutionalité et contrôle de conventionalité. Réflexions autour de l'art. 88-1 de la Constitution dans la jurisprudence du Conseil Constitutionnel. [Communicationd'unCongrès]. Montpellier, 2005.

CANCELA OUTEDA, Celso. El proceso de constitucionalización de la Unión Europea. De Roma a Niza. Santiago de Compostela: Ed. Universidad de Santiago de Compostela, 2001.

CONSTITUCIÓN FRANCESA, Espanha, 1958.

CONSTITUCIÓN ESPAÑOLA, Espanha, 1978.

CONVENCIÓN SOBRE EL ESTATUTO DE LOS REFUGIADOS, de 28 de julio de 1951.

CONVENIO EUROPEO, de 1950 para la protección de los Derechos Humanos y de las libertades fundamentales. 1950.

DIRECTIVA n. 93/13/CEE, del Consejo de 5 de abril. 2013.

FLAMINIO COSTA c. ENEL, ECR 585 (6/64), 1964.

HARO, Ricardo. El control de constitucionalidad comparado y el rol paradigmático de las Cortes y Tribunales Constitucionales. Anuario de Derecho Constitucional Latinoamericano n. 2004. Uruguay: Ed. Konrad Adenauer Stiftung, 2004. p. 41-74.

HERRERA FLORES, Joaquín. Los derechos humanos como productos culturales. Crítica de humanismo abstracto. Madrid: Ed. Catarata, 2005.

KELSEN, Hans. La garantiejurisdictionenelle de la Constitution (La justice constitutionnelle). Revue de Droit Public et de la Science politique en France et à l'étranger, [S.l.], n. 45, p. 197-257, 1928.

LEY FUNDAMENTAL DE LA REPÚBLICA FEDERAL ALEMANA, de 1949.

LEY N. 1/2000, de 7 de enero, de Enjuiciamiento Civil. 2000.

LEY N. 1/2013, de 14 de mayo, de medidas para reforzar la protección a los deudores hipotecarios, reestructuración de deuda y alquiler social. 2013. 
LEY N. 12/2009, de 30 de octubre, reguladora del derecho de asilo y de la protección subsidiaria. 2009.

LEY N. 4/2015, de 30 de marzo, de protección de la seguridad ciudadana. 2015.

LEY ORGÁNICA N. 10/1995, de 23 de noviembre, del Código Penal. 1995.

LEY ORGÁNICA N. 4, de 11 de enero de 2000. Sobre derechos y libertades de los extranjeros en España y su integración social. 2000.

MARTÍNEZ ARRIBAS, Luciano F. El proceso de constitucionalización de la Unión Europea y el modelo de distribución de competencias entre la Unión y los estados miembros. Tesis (Doctoral) - Universidad Santiago de Compostela, 2012. Disponible en: http://dspace.usc.es/ bitstream/10347/6166/1/rep_284.pdf. Acesso em: 15 jun. 2015.

MARTÍNEZ ESTAY, José I. El sistema europeo-continental de justicia constitucional: el control de constitucionalidad en la Unión Europea.

Estudios Constitucionales, Chile, v. 3, n. 2, p. 51-83, 2005.

MILLÁN MORO, Lucía. El ordenamiento jurídico comunitario. Del Tratado Constitucional al Tratado de Lisboa. Revista de Derecho

Comunitario Europeo, Madrid, n. 36, mayo-agosto, p. 401-438, 2010.

MOHAMED AZIZ c. CatalunyaCaixa (Asunto C-415/11).

PELAEZ MARÓN, José Manuel. Lecciones de instituciones jurídicas de la Unión Europea. Madrid: Ed. Tecnos, 2000.

PEREIRA MENAULT, Antonio C. ¿Otro modelo constitucional para Europa? Cuadernos Electrónicos, Santiago de Compostela, n. 4, p. 5790, 2008.

PIOVESAN, Flavia. Direitos Humanos e diálogo entre jurisdições. Revista Brasileira de Direito Constitucional, Brasil, n. 19, jan./jun., p. 67-93, 2012.

PROTOCOLO SOBRE EL ESTATUTO DE LOS REFUGIADOS, de 31 de enero de 1967. 
REAL DECRETO nN. 557/2011, de 20 de abril, por el que se aprueba el Reglamento de la Ley Orgánica 4/2000, sobre derechos y libertades de los extranjeros en España y su integración social, tras su reforma por Ley Orgánica 2/2009.

SAGUÉS, Nestor P. El control de convencionalidad en el sistema interamericano, y sus anticipos en el ámbito de los derechos económicos, sociales y culturales. Concordancias y diferencias con el sistema europeo. In: VON BOGDANDY, Armin; FIX-FIERRO, Hector; FERRER MACGREGOR, Eduardo. Construcción y papel de los derechos sociales fundamentales: Hacia un iusconstitucionalecomune en América Latina. México: Ed. Universidad Nacional Autónoma de México, 2011. p. 381417.

\section{SAUVÉ, Jean-Marc. Le contrôle de constitutionalité en Europe} [Conference] Colloque de droit comparé. Paris, 2011.

SERRATS, Rosa P. La oposición a la ejecución hipotecaria y las cláusulas abusivas. Comentarios a la STJUE de 14 de marzo de 2013 (TJCE, 2013, 89). Caso Mohamed Aziz contra CatalunyaCaixa (Asunto C-415/11). Revista Boliviana de Derecho, Bolivia, n. 19, p. 686-705, 2015.

STC 119/2011, de 15 de Julio.

TOMÉ DA MATA, Edileny. Relación entre los derechos humanos del migrante y su condición sociojurídica. Revista Universita, Madrid, n. 22, p. 90-108, 2015.

TRATADO DE LISBOA, de 2007 por el que se modifica el Tratado de la Unión Europea y el Tratado Constitutivo de la Unión Europea. 2007.

TRATADO de funcionamiento de la Unión Europea de 2012. 2012.

VAN GEND en LOOS c. Administración Fiscal Neerlandesa, del Tribunal de Justicia de las Comunidades Europeas, de 1963.

WHEARE, K. C. Las constituciones modernas. 2. ed. Barcelona: Ed. Labor, 1975. 
Eduardo Biacchi Gomes é Graduado em Direito pela Pontifícia Universidade Católica do Paraná (1993). Mestrado em Direito pela Universidade Federal do Paraná (2000). Especialista em Direito Internacional pela Universidade Federal de Santa Catarina (2001). Doutorado em Direito pela Universidade Federal do Paraná (2003). É Pós-doutor em Estudos Culturais pela Universidade Federal do Rio de Janeiro, com estudos realizados na Universidade de Barcelona. Desenvolveu pesquisa na Universidade de Los Andes, Chile. Estágio de pósdoutoramento na PUCPR, PPGD em Direitos Humanos e Políticas Públicas. Atualmente é professor-adjunto integrante do quadro da UniBrasil. Graduação e Mestrado e Doutorado em Direito. Professor Titular de Direito Internacional da Pontifícia Universidade Católica do Paraná. Professor Adjunto do Curso de Direito Uninter. Tem experiência na área de Direito, com ênfase em Direito Internacional e Direito da Integração, Direitos Humanos, atuando principalmente nos seguintes temas: blocos econômicos, direito comunitário, direito internacional público, direito da integração, Mercosul e direito constitucional, foi consultor jurídico do Mercosul em 2005 e 2006. Foi Editor-Chefe da Revista de Direitos Fundamentais e Democracia, vinculada ao Programa de Mestrado e Doutorado em Direto do UniBrasil, Qualis A1, desde a sua fundação. Hoje, exerce funções no comitê editorial do periódico.

E-mail: eduardobiacchigomes@gmail.com

Endereço profissional: PPGD UniBrasil. Rua Konrad Adenauer, n. 442, Tarumã, Curitiba, PR. CEP: 82821-020.

Edileny Tomé da Mata é Licenciado en Derecho por la Université Mohamed Premier Oujda (Maroc), título reconocido por ENIC-NARIC (Francia). Máster en Derechos Humanos, Interculturalidad y Desarrollo por la Universidad Pablo de Olavide - Sevilla (España) y Doctor CUM LAUDE con acreditación europea por la Universidad Pablo de Olavide - Sevilla (España). Fue Asesor Jurídico en Unión Romaní (España) donde se dedicó al asesoramiento a los grupos poblacionales migrantes comunitarios y extracomunitarios en materias relacionadas con sus condiciones sociales en España (extranjería, sociolaboral, violencia de género, vivienda) (2009-2013). Igualmente trabajó como técnico del Departamento de Programas Sociales y proyectos europeos en Fundación AFIES 
ejerciendo las labores de docencia e investigación (2013-2014). Asimismo, fue coordinador del proyecto europeo "Aulas abiertas" de la ONG IESMALÁ (20142015). Igualmente realizó una estancia postdoctoral con beca del Programa Nacional de Post doc del Ministerio de Educación brasileño (PNPD/CAPES), en Unibrasil (Curitiba - Brasil) (2015-2016), durante la cual realizó un estudio de investigación comparado entre el contexto migratorio brasileño y español.

E-mail: edtome@gmail.com

Endereço profissional: Universidad Pablo de Olavide (UPO). Ctra. de Utrera km 1, 41013, Sevilla, España. 